\title{
Covid-19 risk factors and health protocol compliance among mall employees and officers in Yogyakarta
}

\author{
Yunita Kemala Dewi ${ }^{1}$, Ari Probandari ${ }^{2^{*}}$
}

\section{Submitted:}

August 26th, 2020

Accepted:

January 17th, 2020

Published:

January 27th, 2021

\footnotetext{
${ }^{1}$ Department of Biostatistics, Epidemiology, and Population Health, Faculty Medicine Public Health and Nursing, Universitas Gadjah Mada

${ }^{2}$ Department of Public Health, Faculty of Medicine, Universitas Sebelas Maret
}

*Correspondence: ari.probandari@gmail.com

\begin{abstract}
Purpose: This study aimed to analyze risk factors, compliance with health protocols, and the COVID-19 screening test among mall employees at Yogyakarta city, Indonesia. Methods: We analyzed secondary data from a cross-sectional study in Yogyakarta City from May-August 2020. The population was all employees at all malls in Yogyakarta City who participated in the screening rapid test zero survey conducted by the Yogyakarta City Government. Results: Bivariate analysis showed a significant relationship between ensuring proper mask install $(\mathrm{OR}=6.33, \mathrm{p}=0.023,95 \% \mathrm{Cl}=$ 1.03-38.81), applying a minimum distance of $>1$ meter when outside home $(\mathrm{OR}=27.34, \mathrm{p}=0.001,95 \% \mathrm{Cl}=3.01-248.32)$ and applying a minimum distance of $>1$ meter when at work $(\mathrm{OR}=22.25, \mathrm{p}=0.003,95 \% \mathrm{Cl}=$ 2,45-201.65) with the reactive COVID-19 results. Multivariate analysis showed the most dominant variable associated with the reactive rapid test results is not keeping a minimum distance of $>1$ meter when outside the house with a value of (OR=11.91, $\mathrm{p}=0.047,95 \% \mathrm{Cl}=1.03-137.37)$. Conclusion: The risk factor for Covid-19 for employees and mall staff is physical distancing > 1 meter when outside the house. The city administration should keep working with mall managers to tighten health protocols in malls and other public areas to prevent Covid-19 transmission.
\end{abstract}

Keywords: COVID-19; risk factors; health protocols; Yogyakarta City

\section{INTRODUCTION}

Coronavirus disease, also known as COVID-19, is a contagious disease caused by Severe Acute Respiratory Syndrome Coronavirus-2 (Sars Cov-2). This virus and disease were first reported in Wuhan City, China, at the end of December 2019. Samples of isolates from patients were studied with results indicating coronavirus infection, a new type of beta coronavirus, named 2019 novel coronavirus (2019-nCov) [1]. In Indonesia, the spread of Covid-19 cases is increasing and expanding across regions and countries, accompanied by an increase in the number of cases and deaths. The number of Covid-19 cases as of 15 June 2020 was reported as 39,294 confirmed cases with a total death rate of 2,198 cases (CFR 5.6\%) and 15,123 cases were declared cured which were affected in 431 regencies/cities throughout Indonesia [2]. The Yogyakarta City Government has made various efforts to curb the spread of Covid-19. Initial screening used a rapid test, especially in public areas that have the potential for transmission and spread of disease. This study aimed to analyze risk factors, compliance with health protocols, and the COVID-19 screening test among mall employees at Yogyakarta city, Indonesia. 


\section{METHODS}

This study's data was collected from May-August 2020 and based on the COVID-19 serosurvey from 530 employees of five malls in Yogyakarta city. We also asked respondents to fill in a self-reported questionnaire. We performed a logistic regression by estimating Odds Ratio (OR) with 95\% Confidence Interval (CI) and a significance level of $\mathrm{p}>0.05$.

\section{RESULTS}

Most respondents are based on the age category $17-28$ years $(60.0 \%)$, based on female gender $(52.1 \%)$, high school education (79.6\%), domiciled in the city of Yogyakarta $(85.5 \%)$, working period $>2$ years $(54.8 \%)$, income 1-2 million IDR (56.6\%).

Table 1. Characteristics of participants $(n=530)$

\begin{tabular}{llr}
\hline Variables & & $\%$ \\
\hline Age & $17-28$ year & 60.0 \\
& $>28$ tahun & 39.4 \\
Gender & Male & 47.9 \\
& Female & 52.1 \\
Education & Elementary school & 0.8 \\
& Junior high school & 2.8 \\
& Senior high school & 79.6 \\
& Diploma & 4.9 \\
& Undergraduate & 11.5 \\
Live in the city & Profession & 0.4 \\
& Yes & 85.5 \\
Working experience & No & 14.5 \\
& 2 month - 2 years & 45.2 \\
Salary & $>2$ years & 54.8 \\
& $<1$ million & 1.7 \\
& $1-2$ million & 56.6 \\
& $2-3$ million & 30.6 \\
& $>3$ million & 11.1 \\
\hline
\end{tabular}

The proportion of mall employees with reactive results of Covid-19 screening test was $0.9 \%$. None characteristic in Table 1 has a significant statistical relationship with the result Covid-19 screening test.

As the respondent's clinical information, whether the respondent has had any symptoms of illness in the past 14 days, most symptoms felt by respondents are headache $(9.6 \%)$, runny nose (5.7\%), muscle pain (4.9\%) and cough (4.5\%). Meanwhile, for comorbid diseases, $1.1 \%$ of respondents had hypertension, $0.8 \%$ had diabetes mellitus and $0.2 \%$ had heart disease.

Data on travel history and contact as a risk factor, $0.4 \%$ of respondents had contact with Covid-19 reactive patients. About $1.1 \%$ of respondents had conducted a rapid test before. $0.2 \%$ of respondents had a history of travel abroad, $6 \%$ had a history of trips out of town, $12.1 \%$ of respondents had a history of visiting hospitals/community health centers within the last 14 days. As much as $48.5 \%$ of respondents came to work every day. Most employees had average working hours of respondents $<8$ hours (80.2\%). About $86 \%$ of participants stated space in a shop allows a minimum distance of 1.5 meters from visitors as much as $85.7 \%$. Only about half of participants stated that counters are divided/bounded so they are away from visitors (51.9\%), and the average number of visitors per day is $<20$ people (50.8\%).

Most respondents perceived wearing masks when leaving the house (97.2\%), wearing masks while working (97.2\%), ensuring masks are properly installed (90.2\%), workplaces providing masks for work (73.0\%), and diligently washing hands with soap after activities (91.1\%). While $93.2 \%$ perceived that workplaces provide hand sanitizer, only $41.1 \%$ often use hand sanitizers. 
Table 2. Risk factors of Covid-19 rapid test results among Mall Officers and Employees in Yogyakarta City

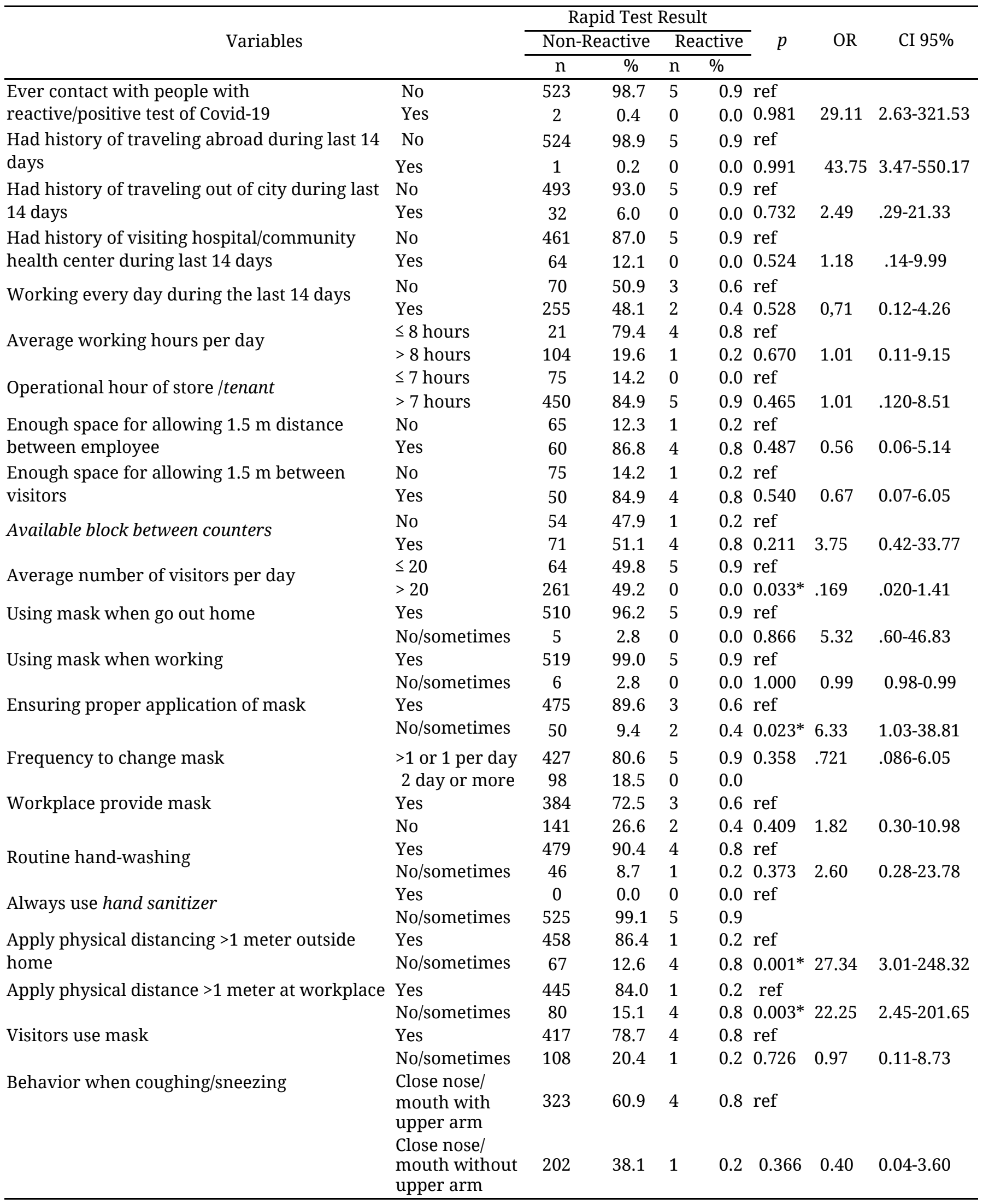

*) means $p<0.05$ Fisher Exact test

Findings revealed that $86.6 \%$ apply at least $>1$ meter distance from other people when outside the house and $84.2 \%$ applying a minimum distance of $>1$ meter while at work. Only 79.4\%, shop visitors using masks, and
$61.7 \%$ cover their mouth/nose with the upper arm when sneezing. More than three quarters (80.8\%) get information through social media. Less than half of 
study informants (41.9\%) quite worried about contacting Covid-19.

The univariate results showed that there was a significant relationship between the number of visitors who come per day, making sure the masks are installed correctly, applying a minimum distance of $>1$ meter when outside the house and applying a minimum distance of $>1$ meter when in the workplace on reactive test results (Table 2). The respondents who do not ensure that the mask is properly installed has a reactive risk of 6.33 times higher than those that are properly installed ( $p=0,023, \mathrm{CI} 95 \% \mathrm{OR}=1.03-38.81$ ). The respondents who do not apply> 1 meter distance guard when outside the house have reactive risk was 27.34 times higher than that of those who applied distance care $(p=0.001, C I=3.01-248.32)$. Meanwhile, the respondents who do not apply> 1 meter distance guard when at work are at risk of reactive 22.25 times compared to those who apply distance control $(\mathrm{p}=$ 0.003, CI = 2.45-201.65).

To identify the most influential variables on the dependent variable, we selected four variables that met the requirements for multivariable analysis $(p<0.25)$ (Table 3). The multivariate results show that the variables that have a significant effect on the results of the rapid test are applying a minimum distance of $>1$ meter when outside the home $(\mathrm{OR}=11.9, \mathrm{p}=0.047,95 \% \mathrm{CI}$ = 1.03-137.37).

Table 3. Multivariable analysis on risk factors of Covid-19 rapid test results among mall officers and employees in Yogyakarta City

\begin{tabular}{|c|c|c|c|c|}
\hline \multicolumn{2}{|l|}{ Variable } & OR & CI 95\% & $p$ value \\
\hline Number of & $\leq 20$ & & ref & \\
\hline visitors & $>20$ & 0 & $0-\infty$ & 0.99 \\
\hline $\begin{array}{l}\text { Ensuring proper } \\
\text { mask use }\end{array}$ & $\begin{array}{l}\text { No or } \\
\text { sometimes } \\
\text { Yes }\end{array}$ & 1.5 & $\begin{array}{c}0.2-11.5 \\
\text { ref }\end{array}$ & 0.73 \\
\hline $\begin{array}{l}\text { Apply physical } \\
\text { distancing }>1\end{array}$ & $\begin{array}{l}\text { No or } \\
\text { sometimes }\end{array}$ & 11.9 & $1.0-137.4$ & $0.05^{*}$ \\
\hline $\begin{array}{l}\text { meter outside } \\
\text { home }\end{array}$ & Yes & & ref & \\
\hline $\begin{array}{l}\text { Apply physical } \\
\text { distancing }>1\end{array}$ & $\begin{array}{l}\text { No or } \\
\text { sometimes }\end{array}$ & 7.5 & $0.65-87.35$ & 0.11 \\
\hline $\begin{array}{l}\text { meter when at } \\
\text { work }\end{array}$ & Yes & & ref & \\
\hline
\end{tabular}

\section{DISCUSSIONS}

Our study found that the number of visitors who come per day, making sure the masks are installed correctly, applying a minimum distance of $>1$ meter when outside the house and applying a minimum distance of $>1$ meter when in the workplace have a significant relationship with the results of the reactive rapid test among mall employees. Among those variables, implemented a distance of $>1$ meter when outside the house was the most dominant variable for the Covid-19 reactive test.

In times of pandemic wearing masks is a must, the government always urges and invites people to always use masks when leaving the house especially in public areas. Several public areas such as hospitals, shopping centers, malls, banks, cafes and other public places have implemented the obligation to wear masks when entering / visiting. People with various characteristics and different backgrounds only obey the rules for wearing masks because it is a requirement to enter / visit but whether they make sure the masks are attached properly is one thing that is different. Ramakrishnan's (2020) research that the average person touches the face 16-24 times an hour, masks have some filtration efficacy and also help people to avoid touching their nose and face without realizing it so that if they are asymptomatic carriers then masks will prevent them from spreading disease extensively [3]. Therefore, if the mask is not installed properly, the virus will be able to enter and infect. This is in accordance with Howard et al's (2020) research that non-medical masks are effective in reducing influenza transmission and have proven effective in small trials conducted in blocking transmission of the coronavirus as well as economic analysis showing that the impact of wearing masks can save thousands of dollars in America [4]. There is a significant relationship between the use of all types of masks to reduce exposure to viruses and the risk of infection at the population level [5]. Transmission may also occur when a person touches a surface that has been contaminated with the coronavirus and then touches the mouth, nose or eyes. Using a mask and ensuring that it is properly installed in public spaces is one way to control the spread of Covid-19 if the application of physical distancing is not always possible. It is very important to comply with government rules and recommendations on preventing the transmission and spread of Covid-19 including how to stay safe even when you are outside the home.

Implementing a minimum distance of $>1$ meter when outside the home is one of the efforts that can be applied in preventing the spread of coronavirus, this effort should be carried out simultaneously with washing hands after activities and wearing a mask when outside the home or at work, as also supported by Chu et al study. The application of physical distance $>1$ meter can reduce the risk of infection by up to $82 \%$, where each additional physical distance of 1 meter can provide more than twofold protection [6]. The combination of using masks and the application of physical distancing can reduce secondary transmission of SARS-CoV-2 quite effectively [7]. The European Center for Disease Prevention and Control (2020) 
physical distancing aims to reduce transmission within a population by minimizing physical contact between potentially infected individuals and healthy individuals or between populations with high transmission rates and populations with low transmission rates [8].

The application of physical distancing is intended so that the number of people infected with the coronavirus does not increase so that the hospital can serve patients optimally considering that the capacity of medical personnel and the capacity of patients in hospitals in Indonesia is very minimal, not to mention the inadequate provision of equipment and facilities. The government calls on people to apply physical distancing and carry out activities from home, including working. However, not a few people have to keep working outside the home either because of the demands of their profession or to support the family economy. Workers who still have to do activities outside the home may still feel fears of contracting Covid-19. The International Labor Organization (2020) has published a list of prevention and mitigation of Covid-19 in the workplace as an effort to reduce the spread of the Covid-19 pandemic in the workplace. One of the things that is being done is to implement physical distance, for example assessing interactions between workers, customers and visitors and implementing measures to reduce the risk of Covid-19 transmission [9]. This research is in line with Kim's findings (2020) until May 15, 2020, as many as 11,018 Covid-19 cases in Korea, $5.7 \%$ of which occurred in the workplace [10]. The policy of implementing physical distancing in the workplace is the key to preventing the Covid-19 outbreak. Meanwhile, the meta-analysis research of Islam et al (2020) found that there was a relationship between physical distancing intervention of $13 \%$ and the Incidence Rate Ratio (IRR $=0.87,95 \%$ CI $0.85-0.89$ ) in the workplace with a decrease in the incidence of Covid-19 globally [11].

To prevent and limit with the spread of Covid-19 in the workplace, employers should apply some health rules and protocols clearly communicate to workers and post announcements to customers that they should not enter workplaces/shops if they are sick even with mild symptoms Workers are encouraged to always monitor their own health and provide personal protective equipment for workers such as masks and providing hand sanitizers in shops. Cashiers are workers who are vulnerable to being exposed to splashes/droplets from customers when they make payments. Cashiers in stores are at risk of contracting Covid-19 because they always make contact with the customer. This is one of the risk factors for coronavirus transmission that must be considered by entrepreneurs and therefore entrepreneurs should put up a barrier/boundary between cashiers and customers with transparent glass or plastic. Some shops in malls have individually taken the initiative by installing bulkheads around counters to reduce exposure and protect workers and cashiers from coronavirus contamination. This boundary or bulkhead installation aims to reduce exposure to splashes/droplets of saliva when customers interact with cashiers in the form of talking, coughing or sneezing, but not all shops in malls do so. The Government of Canada (2020) suggests several important things for business owners, wholesalers and retailers to implement appropriate steps to prevent and reduce the spread of Covid-19 among workers and customers, one of which is to install transparent dividers or plexiglass at the checkout to protect workers from possible exposure to coronavirus [12].

\section{CONCLUSION}

This study concluded a significant relationship between some behaviors of mask use, physical distancing outside the house and at the workplace and the available bounded counter with the reactive rapid test of Covid-19. The City Government should collaborate with the management of malls to tighten health protocols through a circular mandatory wearing masks, conduct initial screening before entering the mall with body temperature checks as an effort to prevent Covid-19 transmission. Mall management should place more security guards (security guards) in many mall locations so that they can directly supervise and admonish both visitors and shop employees who are not wearing masks or who are seen crowding. The mall management provides education both in the form of announcements and advertisements for the application of physical distancing through the mall's loudspeaker. In addition, the mall management should only open 1 entrance and exit so that it is easier to monitor visitors who come. The cooperation with shop owners to limit the number of people in the mall and shop in order to prevent a congestion in the number of visitors so that visitors can more easily implement physical distancing is needed.

\section{REFERENCES}

1. Wang CHY, Li X, Ren L, Zhao J, Hu Y, Zhang L, et al. Clinical features of patients infected with 2019 novel coronavirus in Wuhan, China. Lancet. 2020;395: 497-506.

2. Kemenkes. Covid-19 Indonesia 14 Juni 2020. In: Kementerian Kesehatan. 2020.

3. Ramakrishnan D. COVID-19 and Face Masks--To Use or Not to Use! Indian Journal of Community 
Health. 2020;32.

4. Howard J, Huang A, Li Z, Tufekci Z, Zdimal V, van der Westhuizen H-M, et al. An evidence review of face masks against COVID-19. Proceedings of the National Academy of Sciences of the United States of America. 2021;118. doi:10.1073/pnas.2014564118

5. van der Sande M, Teunis P, Sabel R. Professional and home-made face masks reduce exposure to respiratory infections among the general population. PLoS One. 2008;3: e2618.

6. Chu DK, Akl EA, Duda S, Solo K, Yaacoub S, Schünemann HJ, et al. Physical distancing, face masks, and eye protection to prevent person-to-person transmission of SARS-CoV-2 and COVID-19: a systematic review and meta-analysis. Lancet. 2020;395: 1973-1987.

7. MacIntyre CR, Wang Q. Physical distancing, face masks, and eye protection for prevention of COVID-19. The Lancet. 2020. pp. 1950-1951.

8. ECDC. Considerations Relating to Social Distancing Measures in Response to the COVID-19 Epidemic. In: European Centre for Disease Prevention and
Control [Internet]. 2020. Available:

https://www.ecdc.europa.eu/en/publications-data/ considerations-relating-social-distancing-measure s-response-covid-19-second

9. ILO. Dalam menghadapi pandemi: memastikan keselamatan dan kesehatan di tempat kerja -- Hari K3 Se-Dunia 2020. In: International Labour Organization [Internet]. 2020. Available: https://www.ilo.org/jakarta/whatwedo/publication s/WCMS_742959/lang--en/index.htm

10. Kim E-A. Social Distancing and Public Health Guidelines at Workplaces in Korea: Responses to Coronavirus Disease-19. Safety Health Work. 2020;11: 275-283.

11. Kellerman RD, Rakel D. Conn's Current Therapy 2021, E-Book. Elsevier Health Sciences; 2020.

12. Public Health Agency of Canada. Advice for essential retailers during COVID-19 pandemic. 18 Sep 2020 [cited 19 Jan 2021]. Available: https://www.canada.ca/en/public-health/services/d iseases/2019-novel-coronavirus-infection/guidance -documents/advice-essential-retailers.html 